\title{
A PRODUÇÃO DO OUTRO INCLUÍDO EM TEMPOS DE AVALIAÇÕES EM LARGA ESCALA \\ http://dx.doi.org/10.5902/2318133841486
}

\author{
Kamila Lockmann ${ }^{1}$ \\ Roseli Belmonte Machado²
}

\begin{abstract}
Resumo
As avaliações em larga escala têm se tornado cotidianas no meio educacional. Seus propósitos são o de mensurar a qualidade da educação. Contudo, compreende-se que tais avaliações também produzem e qualificam sujeitos. No Brasil uma das recentes avaliações é a Avaliação Nacional da Alfabetização - ANA -, sobre a qual temos problematizado o modo como os sujeitos com deficiência têm sido produzidos. Nesta pesquisa o objetivo foi o de analisar a produção do sujeito com deficiência nas escolas públicas a partir da Avaliação Nacional da Alfabetização. Para tanto foram analisados documentos que compõe e regulam essa avaliação e foram realizadas entrevistas com professores e diretores de escolas públicas de sete municípios gaúchos. Os dados foram analisados com base nos Estudos Foucaultianos. Destaca-se que a ANA contribuiu para a constituição do outro com deficiência como um sujeito incapaz e invisível a esses avaliadores.

Palavras-chave: avaliação em larga escala; sujeito; inclusão escolar; currículo.
\end{abstract}

\section{THE PRODUCTION OF THE OTHER INCLUDED IN TIMES OF LARGE-SCALE EVALUATION}

\section{Abstract}

The large scale evaluations have become everyday in the educational field. Its purposes are to measure education quality. However, it is understood that such evaluations also produce and qualify the subjects. In Brazil, one of the recent evaluations is the National Literacy Assessment ANA -, in which we have problematized the way on how the subjects with disabilities have being produced. In this research, the objective was to analyze the production of disabled subjects in public schools based on the National Literacy Assessment. For this purpose, documents that compose and regulate this evaluation were analyzed and interviews were conducted with teachers and principals of public schools in seven counties from Rio Grande do Sul state. Data were analyzed based on Foucaultian Studies. It is noted that ANA contributed to the constitution of the other with disabilities as an incapable and invisible subject to these evaluators.

Key-words: large scale evaluation; subject; school inclusion; curriculum.

\footnotetext{
1 Universidade Federal do Rio Grande, Brasil. E-mail: kamila.furg@gmail.com.

2 Universidade Federal do Rio Grande do Sul, Brasil. E-mail: robelmont@yahoo.com.br.

\begin{tabular}{|l|l|l|ll}
\hline Regae: Rev. Gest. Aval. Educ. & Santa Maria & v. 9 & n. 18 & Pub. contínua 202
\end{tabular}

Pub. contínua 2020 p. $1-11$
} 


\section{Introdução}

A discutir sobre as avaliações em larga escala Veiga Neto (2012) destaca que vivemos, na atualidade, uma invasão de práticas avaliativas por toda a parte. A lista é interminável: Provinha Brasil ${ }^{3}$, Avaliação Nacional do Rendimento Escolar - Anresc, também conhecida como Prova Brasil ${ }^{4}$-; Avaliação Nacional da Educação Básica - Aneb ${ }^{5}$; Avaliação Nacional de Alfabetização - ANA ${ }^{6}$; Exame Nacional para Certificação de Competências de Jovens e Adultos - Enceja ${ }^{7}$; Prova Nacional Docente $^{8}$, Avaliação Nacional da Educação Infantil - Anei ${ }^{9}$; Exame Nacional do Ensino Médio - Enem ${ }^{10}$; Exame Nacional de Desempenho dos Estudantes - Enade ${ }^{11}$. Essas são algumas das avaliações que circulam contemporaneamente e produzem efeitos sobre a escola e o currículo, mas também sobre os sujeitos escolares.

Instigadas por esse cenário de avaliações que se prolifera, ou por esse delírio avaliatório agonístico (Veiga-Neto, 2012), passamos a olhar para uma dessas avaliações: a Avaliação Nacional de Alfabetização - ANA. Nosso intuito é o de investigar como os sujeitos com deficiência têm sido produzidos no ambiente escolar a partir da ANA.

É importante ressaltar que a escolha da ANA decorreu por percebermos que ela é umas das primeiras avaliações em larga escala a considerar a presença dos alunos de inclusão na aplicação das provas. A Avaliação Nacional de Alfabetização pode ser compreendida como um primeiro movimento produzido nas avaliações em larga escala, uma vez que é a primeira forma de avaliação que cogita a possibilidade, não só, de elaborar instrumentos adaptados, mas também de discutir a construção de matrizes específicas considerando os alunos incluídos.

${ }^{3}$ A Provinha Brasil foi aplicada pela primeira vez em 2008 e pretende investigar o desenvolvimento das habilidades relativas à alfabetização e ao letramento em Língua Portuguesa e Matemática, desenvolvidas pelas crianças matriculadas no $2^{\circ}$ ano do ensino fundamental das escolas públicas brasileiras.

${ }^{4}$ A Prova Brasil compõe o Saeb desde 2015 e direciona-se os alunos do 5ำ e 9ano do ensino fundamental das escolas públicas das redes municipais, estaduais e federal, com o objetivo de avaliar a qualidade do ensino.

${ }^{5}$ A Avaliação Nacional da Educação Básica abrange, de maneira amostral, alunos das redes públicas e privadas do país, em áreas urbanas e rurais, matriculados no $5^{\circ}$ e $9^{\circ}$ ano do ensino fundamental e no $3^{\circ}$ ano do ensino médio.

6 A Avaliação Nacional da Alfabetização é uma avaliação censitária envolvendo os alunos do 3ํano do ensino fundamental das escolas públicas, com o objetivo principal de avaliar os níveis de alfabetização e letramento em Língua Portuguesa, alfabetização Matemática e condições de oferta do ciclo de alfabetização das redes públicas. A ANA foi incorporada ao Saeb pela portaria $\mathrm{n}$. 482, de 7 de junho de 2013.

7 O Encceja constitui-se em um exame para aferição de competências, habilidades e saberes adquiridos pelos jovens e adultos residentes no Brasil e no exterior que não tiveram oportunidade de concluir seus estudos em idade própria.

8 A Prova Nacional Docente tem o objetivo principal de subsidiar os Estados, o Distrito Federal e os municípios na realização de concursos públicos para a contratação de docentes para a educação básica. Trata-se de uma prova anual, a ser aplicada de forma descentralizada em todo o país para os candidatos ao ingresso na carreira docente das redes de educação básica.

9 Avaliação Nacional da Educação Infantil, prevista para iniciar em 2016, pretende avaliar o atendimento à demanda por ensino infantil, a formação dos profissionais que atuam com crianças e a disponibilidade de brinquedos.

10 O Exame Nacional do Ensino Médio foi criado em 1998 com o objetivo de avaliar o desempenho do estudante ao fim da educação básica.

11 O Exame Nacional de Desempenho dos Estudantes foi criado junto com o Sistema Nacional de Avaliação Superior, pela lei n. 10.861, de 14 de abril de 2004.

\begin{tabular}{|l|l|l} 
Regae: Rev. Gest. Aval. Educ. & Santa Maria & v. 9
\end{tabular}

9

ก. 18

Pub. contínua 2020

p. 1-11 


\section{Caminhos da pesquisa}

Nosso objetivo foi o de analisar a produção do sujeito com deficiência nas escolas públicas a partir da Avaliação Nacional da Alfabetização. Para isso a pesquisa foi estruturada em dois momentos metodológicos. Primeiro a análise documental de leis e regulamentos que legislam sobre a Avaliação Nacional de Alfabetização com vistas à compreensão dos documentos que compõem esta etapa.

Tabela 1 -

Documentos analisados na ANA.

\begin{tabular}{|c|c|c|}
\hline Documento & Síntese & Site \\
\hline $\begin{array}{l}\text { Avaliação } \\
\text { Nacional de } \\
\text { Alfabetização: } \\
\text { documento } \\
\text { básico }\end{array}$ & $\begin{array}{l}\text { Torna pública a proposta do Inep da } \\
\text { Avaliação } \quad \text { Nacional } \quad \text { da } \\
\text { Alfabetização. }\end{array}$ & $\begin{array}{l}\text { http://download.inep.gov.br/educacao } \\
\text { _basica/saeb/ana/documento/2014/d } \\
\text { ocumento_basico_ana_online_v2.pdf }\end{array}$ \\
\hline $\begin{array}{l}\text { Portaria n. } 867 \text { de } \\
4 \text { de julho de } \\
2012 .\end{array}$ & $\begin{array}{l}\text { Institui o Pacto Nacional pela } \\
\text { Alfabetização na Idade Certa e as } \\
\text { ações do Pacto. }\end{array}$ & http://portal.inep.gov.br/web/saeb/ana \\
\hline $\begin{array}{l}\text { Portaria n. } 482 \text { de } \\
7 \text { de junho de } \\
2013 .\end{array}$ & $\begin{array}{l}\text { Dispõe sobre o Sistema de } \\
\text { Avaliação da Educação Básica - } \\
\text { Saeb. }\end{array}$ & $\begin{array}{l}\text { http://portal.inep.gov.br/web/saeb/an } \\
\text { a }\end{array}$ \\
\hline $\begin{array}{l}\text { Portaria n. } 304 \text { de } \\
21 \text { de junho de } \\
2013 .\end{array}$ & $\begin{array}{l}\text { Dispõe sobre o Sistema de } \\
\text { Avaliação da Educação Básica - } \\
\text { Saeb }\end{array}$ & http://portal.inep.gov.br/web/saeb/ana \\
\hline $\begin{array}{l}\text { Portaria n. } 120 \text { de } \\
19 \text { de março de } \\
2014:\end{array}$ & $\begin{array}{lccc}\text { Dispõe } & \text { sobre } & \text { os } & \text { resultados } \\
\text { Preliminares ANA } 2013 & \end{array}$ & http://portal.inep.gov.br/web/saeb/ana \\
\hline $\begin{array}{l}\text { Portaria } n .468 \text { de } \\
19 \text { de setembro } \\
\text { de } 2014 .\end{array}$ & $\begin{array}{l}\text { Estabelece a sistemática para a } \\
\text { realização da edição de } 2014 \text { da } \\
\text { ANA }\end{array}$ & http://portal.inep.gov.br/web/saeb/ana \\
\hline $\begin{array}{l}\text { Nota explicativa - } \\
\text { ANA - } 2013\end{array}$ & $\begin{array}{l}\text { Apresenta explicação sobre a } \\
\text { sistemática da ANA, seus } \\
\text { instrumentos e metodologias. }\end{array}$ & $\begin{array}{l}\text { http://download.inep.gov.br/educacao } \\
\text { basica/saeb/ana/resultados/2013/not } \\
\text { a explicativa ana 2013.pdf }\end{array}$ \\
\hline
\end{tabular}

Fonte: autores.

A segunda etapa investigativa se dirigiu a definir municípios gaúchos para participarem da pesquisa e a selecionar escolas nesses municípios. Os municípios foram: Rio Grande; Pelotas; Porto Alegre; São Leopoldo; Lajeado; Bento Gonçalves e Alegrete. Em cada município foram escolhidas duas escolas. Para selecionar as escolas foi realizado contato com as Secretarias de Educação a fim de coletar informações sobre o número de alunos com deficiência por escola em cada rede municipal de ensino. De posse dessas informações buscamos fazer a seleção de duas escolas em cada município que tinham o maior número de alunos incluídos considerando os laudos médicos e o critério de vulnerabilidade social. Esse critério foi estabelecido considerando que nestas escolas podíamos analisar o paradoxo que as professoras vivenciam, cotidianamente, entre as avalições em larga escala e a inclusão escolar. 
Após a seleção das escolas foram realizadas entrevistas semiestruturadas com os diretores das escolas e aplicados questionários com os professores que atuam no Ciclo de Alfabetização, por estes estarem diretamente vinculados à ANA. As referidas entrevistas com os diretores, assim como os questionários com os professores, abordaram aspectos presentes nos objetivos da pesquisa, tentando perceber como essas verdades que circulam por meio das avaliações em larga escala e da inclusão acabam produzindo o sujeito com deficiência.

Perguntas aos docentes: a) Quando foi aplicada a ANA em sua turma você tinha alunos de inclusão? Eles realizaram a prova? b) Em sua opinião a ANA considera as necessidades especiais dos alunos? Há diferenças em relação a aplicação da prova para alunos com alguma deficiência? Se sim, quais? c) Há alguma adequação de conteúdo para alunos com deficiência? Se sim, quais? Como é feito? d) Existe material adequado no momento de aplicação da prova para atender as especificidades dos alunos com necessidades especiais? e) Aqueles alunos que possuem deficiência e que tem um monitor (professor auxiliar), este permanece acompanhando o aluno no momento da prova? Pergunta aos diretores: Os alunos considerados de inclusão, eles participam do momento da prova?

\section{A produção do outro da inclusão}

Em Verdade e poder, Foucault (1992), ao ser questionado sobre a abordagem genealógica, afirma que é preciso livrar-se de uma ideia de sujeito constituinte e chegar a um tipo de análise que entenda a constituição do sujeito na trama histórica. Com base nesse pensamento esta pesquisa problematiza como os sujeitos com deficiência têm sido produzidos no ambiente escolar a partir da ANA. Entendemos que não há um sujeito mesmo com deficiência, mas um sujeito contingente compreendido pelo a priori histórico, pelos modos de objetivação - em práticas de saber e de poder - e modos de subjetivação - na relação do sujeito com as verdades - que o constituíram em um ou outro modo.

Foucault (1992), ao enfatizar sua preocupação com a constituição do sujeito, propôs um deslocamento das práticas de objetivação e passou a considerar e a descrever o modo pelo qual um sujeito se torna ele próprio um sujeito. Utilizando-se de um aporte de textos e escritos da Antiguidade Greco-Romana, o autor abordou acerca das práticas de si em diferentes racionalidades e, ao mesmo tempo, mostrou técnicas que exigem do sujeito que diga a verdade sobre si mesmo. Como aponta Avelino (2011), ao pensarmos sobre essa verdade importa o seu poder e seus efeitos na subjetivação dos sujeitos, ou seja, "o que está em jogo não é a censura ou aceitação do discurso verdadeiro, mas o poder da ade e seus efeitos sobre a subjetividade" (p. 36). É um entendimento sobre a verdade que se afasta do transcendental e se desloca para uma verdade imanente que vincula o sujeito a si mesmo.

Assim, considera-se que diferentes modos de objetivar o sujeito com deficiência dentro da escola, incluindo as avaliações em larga escala, o produz e o constitui por entremeados processos de subjetivação. Na ANA, por exemplo, podemos ver esses modos de subjetivação presentes nos documentos que compõe essa avaliação, bem como nas falas dos entrevistados. 


\section{A ANA e o aluno de inclusão}

Por um lado, analisando os documentos que legislam sobre a ANA, percebemos a vontade de capturar a todos os sujeitos que se faz presente na materialidade dos ditos. Por outro lado, a partir das manifestações dos diretores e professores, visualiza-se um movimento de invisibilidade e discriminação desses sujeitos em tais processos.

Nesse contexto, uma das principais questões a ser levantada é sobre a participação dos alunos com deficiência na realização das provas. Analisando os documentos selecionados para realização desta pesquisa percebemos que se faz presente em seus ditos a necessidade de participação de todos os sujeitos nas avaliações.

Art. 5 Cada unidade escolar poderá fazer uso de seus recursos de Atendimento Educacional Especializado - AEE, para garantir melhores condições de atendimento, acessibilidade e participação nas avaliações aos estudantes com deficiência, transtornos globais ou específicos do desenvolvimento, síndromes ou outras necessidades especiais. (Brasil, 2014, p. 26)

Garantir atendimento, acessibilidade e participação de todos os sujeitos nas avaliações é o imperativo que se faz presente nos ditos legais analisados nesta pesquisa. Vemos aqui a necessidade que essas avaliações apresentam de capturar todos os sujeitos. Ninguém pode ficar fora do jogo da performatividade e todos precisam ser contabilizados nos índices que medem os desempenhos dos alunos em alfabetização.

A inclusão se constitui num imperativo contemporâneo, ou seja, se impõe a todos como verdade absoluta e inquestionável, como princípio que mobiliza nossas vidas e nossas ações. As políticas de avaliação externa em larga escala não ficam fora desse jogo e obedecem, também, a esse imperativo. Elas precisam contemplar e incluir a todos, porém, ao fazer isso produzem, ao mesmo tempo, movimentos de inclusão - porque incluem todos no jogo - e exclusão, porque por dentro desse movimento de incluir, excluem. Tais processos de exclusão podem ser percebidos das manifestações dos diretores e professores quando se referem à participação dos alunos de inclusão na realização das provas. A maioria comunica que possuíam alunos considerados de inclusão no dia da aplicação da ANA e estes realizaram a avaliação. Assim, percebe-se que essa avaliação procura, como está esclarecido nos documentos que a compõe, considerar a presença dos alunos de inclusão na aplicação das provas.

Todavia, ao compreender a diferença como algo inerente ao social e, desse modo ao contexto educacional, nos preocupa entender a forma pela qual a ANA considera o aluno dito de inclusão durante as avaliações. Ao serem questionados sobre tal ponto, a maior parte dos docentes narrou dificuldades nesse processo:

"Não considera. O aluno que apliquei a prova era autista e eu li a prova para ele." (Professor D8)

"Creio que não, pois as provas não são diferenciadas e não há pessoas que auxiliem de forma direcionada na realização destas. Os alunos necessitam de um certo acompanhamento ou auxilio." (Professor D9)

"A prova ANA não considera as necessidades dos alunos especiais, não havendo diferença em sua aplicação." (Professor D10) 
"Não foi aplicada para esses alunos." (Professor D11)

"Não considera. Não há diferença, pois até o monitor teve que sair da sala." (Professor A2)

"Não há inclusão na prova. O monitor não pode ficar com o aluno incluído no momento da prova." (Professor A10)

"Não, pois em 2013, primeiro ano que foi a aplicação da ANA, eu tinha dois alunos inclusos e a prova que fizeram foi a mesma e um não pode permanecer com a monitora, pois elas não tinham a informação do caso de inclusão." (Professor A13)

"Participam quando tem autonomia para realizar a prova sem o auxílio do professor." (Diretora D)

Os processos de exclusão materializados nessas manifestações são de duas ordens: ou os alunos de inclusão não participam das provas, o que de certa forma mascara o resultado da turma e o índice obtido pela escola, promovendo assim um processo de invisibilidade desses sujeitos não só na aplicação das provas, mas também nos resultados expressos pelas avaliações externas, ou os alunos participam das avaliações sem terem suas especificidades contempladas. Percebe-se que a aplicação da ANA não considera a especificidade de cada aluno, principalmente daqueles com deficiência, o que, de certo modo, pode não mostrar as capacidades desses sujeitos os marcando como aqueles que estão à margem do processo educacional. Quando essas avaliações são aplicadas a todos sem considerar a diferença, trata de reforçar a ideia de uma diferença negativa e pormenorizada, talvez resultado do que Lopes e Veiga-Neto (2011) chamaram de uma discriminação negativa por "terem ou assumirem determinadas identidades de gênero, de raça/etnia, etc." (p. 122). Todos estão no processo, mas com seus lugares marcados e esperados.

Lopes e Fabris (2013) nos lembram que no neoliberalismo não mais interessa excluir do sistema os diferentes, o que se deseja é que todos estejam inclusos na lógica da concorrência, embora em diferentes gradientes de inclusão. A inclusão, via políticas de inclusão escolares, sociais, assistenciais e de trabalho, pode funcionar como uma ação do jogo econômico. Ao estarem incluídas nos grupos, nos registros oficiais, no mercado de trabalho, nas cotas de bolsa-assistência, na escola, nas avaliações, etc., as pessoas tornam-se alvos das ações do Estado. Trata-se de ações que visam à conduzir as condutas humanas dentro de um jogo com regras definidas no interior dos distintos e dos muitos grupos sociais que continuam marcando as diferenças.

A partir dessas considerações é possível debater que as reivindicações de direitos das minorias - das mais distintas ordens - e os movimentos sociais que trabalham em prol da inclusão nas benesses do Estado, na sociedade e na escola, são usados como instrumentos dentro do jogo neoliberal. Um desses instrumentos é as avaliações em larga escala, como o caso da ANA. Dessa forma entende-se que uma das regras da racionalidade atual, considerando o neoliberalismo, é a não exclusão (Foucault, 2008), bem como a inclusão, a partir de uma possível garantia de melhores condições de vida, 
de universalização e igualdade de direitos individuais, é uma estratégia social e política que governa os diferentes sujeitos e permanece marcando as diferenças. Diferenças essas que, no caso dos alunos considerados incluídos no ambiente escolar, é vista como negativa.

\section{Adaptações curriculares}

O segundo enfoque que destacamos na pesquisa diz respeito às adaptações curriculares. Ao analisar os ditos materializados nos documentos nos parece possível afirmar que vivemos um movimento de adaptação desenvolvido pelas avaliações em larga escala. Adaptações no sentido de considerar aspectos locais e regionais, por exemplo, por meio dos questionários de contexto, e adaptações com o intuito de incluir os diferentes sujeitos heterogêneos no jogo da homogeneidade. O esforço dessas políticas parece ser o de mostrar à população que elas consideram todos aqueles aspectos que eram apontamos como silenciados ou apagados nesses instrumentos de avaliação:

O Inep prevê na ANA o desenvolvimento de ações com vistas ao atendimento específico para alunos com necessidades educativas especiais. Nesse sentido, vem discutindo o desenvolvimento de estratégias distintas, tais como construção de matrizes específicas e elaboração de instrumentos adaptados. (Brasil, 2013, p. 7)

Além disso, a portaria n. 468, de 19 de setembro de 2014, que estabelece a sistemática para a realização da edição 2014 da ANA, apresenta algumas estratégias para garantir condições de participação aos sujeitos incluídos nas escolas regulares. Ela destaca:

Art. 4 ${ }^{\circ}$ A ANA 2014 será realizada no período de 17 a 28 de novembro de 2014, em todos os Estados e no Distrito Federal. § 1 O Inep disponibilizará provas ampliadas (em fonte 18) e superampliadas (em fonte 24) para os estudantes com baixa visão, de acordo com os dados fornecidos pelas unidades escolares no Censo Escolar 2014. § 2 Será assegurado tempo adicional aos estudantes com deficiência, transtornos globais ou específicos do desenvolvimento, síndromes ou outras necessidades especiais. (Brasil, 2014)

Diante do exposto pelos documentos e ao estender a ANA a todos os alunos parece ficar evidente que as necessidades individuais dos sujeitos estão sendo contempladas para que cada um possa realizar essa avaliação. Preocupamo-nos em problematizar uma adequação de conteúdos, o auxílio com materiais adaptados e a presença de aplicadores capacitados para um atendimento individualizado. Para tanto, conversamos com os professores sobre esses pontos:

"Não sei se teve adaptação porque meus alunos não tinham deficiência visual ou auditiva." (Professor E4)

"Eles não fizeram a prova (os alunos são deficientes, não leem, nem escrevem na sua maioria." (Professor D11)

“Não há adequação, as provas são todas iguais.” (Professor A10) 
"Não sei se para todos, mas com dois casos de inclusão que tinham na minha sala, não." (Professor A13)

"Não porque as professoras que aplicam as provas pedem que os monitores saiam e se os alunos com deficiência não quiserem fazer a prova podem sair da sala de aula." (Professor A1)

"O aplicador pede que o monitor retire-se da sala." (Professor A10)

"Em 2013, quando recebi a ANA tinha uma aluna autista que não queriam deixar a monitora permanecer com ela por não constar nos dados da aplicadora determinada necessidade." (Professor A13)

Ao se prestar atenção para as contribuições dos professores notamos que, em sequência das respostas anteriores, a aplicação da ANA não considera as especificidades de cada aluno, embora seja destinada a todos. Não há adaptação de materiais ou subsídio àqueles que precisam. Em alguns casos o monitor que os acompanha cotidianamente na escola é impedido de auxiliar os alunos na realização da avaliação. Não obstante os conteúdos da avaliação são os mesmos para todos os alunos, o que evidencia que não há uma ponderação sobre o currículo da prova, embora, muitas vezes, assegurados pela legislação, tais alunos tenham uma estrutura curricular adaptada na escola.

Nos trabalhos de Veiga-Neto (2006; 2008; 2012; 2013; 2014) podemos encontrar importantes colaborações no que tange às discussões sobre currículo e de que modo esse artefato vai constituindo sujeitos em relações de saber-poder. Para o autor o currículo é entendido como um artefato cultural inventado há pouco mais de quatro séculos para colocar ordem na educação escolar. O currículo funcionou como maquinaria disciplinar, uma máquina espaço-temporal a formar e a formatar indivíduos disciplinares. Sua invenção, para Veiga-Neto (2013), está pautada com o processo de ordenamento, a partir da Modernidade, em relação as disciplinas que se desenvolveram no eixo do corpo e dos saberes. Isso vem ao encontro das considerações de Bauman (2001) que destaca a busca pela ordem estabelecida na Modernidade.

Ainda para Veiga-Neto (2014), "a disciplina aplicada no eixo do corpo traz, como resultado, a criação de corpos dóceis e, em consequência, almas dóceis, sujeitos dóceis. Como eu tenho argumentado, no eixo dos saberes a disciplina produz o mesmo efeito" ( $p$. 1). É na articulação entre o eixo do corpo e o eixo dos saberes que se inventa, se dissemina e se consolida um tipo de sujeito: o sujeito moderno. Assim, o currículo não deve ser entendido e problematizado numa dimensão reduzida à epistemologia tradicional ou numa dimensão restrita a qualquer ideologia, seja ela de matriz política, econômica, cultural ou filosófica: "Ele deve ser pensado a partir de complexas miradas sobre o social; miradas ao mesmo tempo panorâmicas e focais, abrangentes e específicas, disciplinares e transdisciplinares, macroscópicas e microscópicas" (Veiga-Neto, 2014, p. 1).

Nessa perspectiva destaca-se a compreensão de currículo como artefato que constitui sujeitos e práticas, podendo contribuir para reforçar as questões da diferença, ou seja, marcar aquilo que é visto como dentro de uma ordem ou aquilo que a escapa. Quando não são pensadas adaptações para que os alunos com deficiência sejam capazes de realizar a ANA, temos o estabelecimento de um tipo específico de currículo que, ao constituir o sujeito com deficiência, vai ao encontro da produção de diferenças negativas. 


\section{Considerações sobre os modos de pensar o outro}

Estudos têm apontado que a vontade de incluir as distintas diferenças na escola gera constantes relações de exclusão. Lopes $(2004,2007,2009)$ e Lopes e Fabris (2013) afirmam que quando se trata da inclusão na escola deve-se compreender a existência do termo in/exclusão como uma unidade de sentido, um conceito que, na racionalidade atual, não é dissociado. Nessa compreensão não há uma relação em que exista apenas a inclusão ou a exclusão, e sim que esses processos são interdependentes e por isso podem ser vistos como uma unidade de sentido: processo de in/exclusão. Também para Veiga-Neto e Lopes (2007)

as instituições que garantem o acesso e o atendimento a todos são, por princípio, includentes, mesmo que, no decurso dos processos de comparação e classificação, elas venham a manter alguns desses "todos" (ou muitos deles...) em situação de exclusão. Isso significa que o mesmo espaço considerado de inclusão pode ser considerado um espaço de exclusão. Conclui-se assim que a igualdade de acesso não garante a inclusão e, na mesma medida, não afasta a sombra da exclusão. (p. 959)

In/exclusão é uma expressão criada para mostrar que, embora muitos estejam incluídos nas estatísticas e em alguns espaços físicos e sociais, boa parcela dos indivíduos ainda sofre com as práticas de inclusão excludentes (Lopes; Fabris, 2013). Inclusão e exclusão estão articuladas dentro de uma mesma matriz epistemológica, política, cultural e ideológica. Talvez, nesse sentido, ao compreender que, a partir da diferença, se produz a inclusão e a exclusão no cotidiano da escola, seja possível pensarmos outros modos de estar com o outro.

No contexto de um delírio avaliatório agonístico (Veiga-Neto, 2012) e da inclusão como um imperativo do Estado brasileiro, compreendemos que a ANA, ao objetivar alunos com deficiência dentro da escola, também se materializa no rol dos processos de in/exclusão. Vimos nos documentos que compõe e regulam a ANA uma busca de garantir a participação de todos os sujeitos na realização das avaliações, incluindo aqueles que historicamente vêm sendo silenciados. Como dissemos, foram realizadas adaptações, de diversas ordens, procurando incluir os sujeitos heterogêneos no jogo da homogeneidade.

Todavia, ao analisar o modo como a ANA está sendo aplicada nos espaços escolares, percebemos que essa avaliação tem contribuído para a constituição do outro com deficiência de dois modos: como um sujeito invisível ou incapaz para esses avaliadores. Por um lado temos os alunos com deficiência não participando das provas, não mostrando a realidade da turma e, portanto, promovendo a invisibilidade desses sujeitos. Já por outro lado temos os alunos com deficiência que participam das avaliações sem terem suas especificidades contempladas e assim sendo marcados pela incapacidade. Isso colabora para que, sobre esse sujeito, seja produzida uma diferença negativa. Uma diferença que traz as marcas da incapacidade, do fracasso e dos que não aprendem. Um conceito que pode ser compreendido dentro do rol dos processos de in/exclusão escolares.

A partir dessas reflexões nos posicionamos ao lado daqueles que pensam em outras possibilidades de estar com o outro e de viver a diferença. Para tanto é que nos propomos a olhar esse processo e refletir sobre suas entrelinhas e os possíveis espaços de luta e resistência que podem vir a existir. 


\section{Referências}

AVELINO, Nildo. Apresentação: Foucault e a anarqueologia dos saberes. In: FOUCAULT, Michel. Do governo dos vivos: curso no Collège de France 1979-1980: excertos. São Paulo: Achiamé, 2011.

FOUCAULT, Michel. Microfísica do poder. Rio de Janeiro: Graal, 1992.

FOUCAULT, Michel. Nascimento da biopolítica. São Paulo: Martins Fontes, 2008.

LOPES, Maura Corcini. A inclusão como ficção moderna. Pedagogia: a revista do curso, São Miguel do Oeste, v. 3, n. 6, 2004, p. 7-20.

LOPES, Maura Corcini. Inclusão escolar, currículo, diferença e identidade. In: LOPES, Maura Corcini, DAL'IGNA, Maria Cláudi (orgs.). In/exclusão nas tramas da escola. Canoas: Ulbra, 2007, p. 11-33.

LOPES, Maura Corcini. Políticas de inclusão e governamentalidade. Educação e Realidade, Porto Alegre, v. 34, n. 2, 2009, p. 153-170.

LOPES, Maura Corcini; FABRIS, Elí Henn. Inclusão e educação. Belo Horizonte: Autêntica, 2013.

VEIGA-NETO, Alfredo. Dominação, violência, poder e educação escolar em tempos de Império. In: RAGO, Margareth; VEIGA-NETO, Alfredo (orgs.). Figuras de Foucault. Belo Horizonte: Autêntica, 2006, p.13-38.

VEIGA-NETO, Alfredo. Crise da modernidade e inovações curriculares: da disciplina para o controle. In: PERES, Eliane et. al (orgs.). Trajetórias e processos de ensinar e aprender: sujeitos, currículos e culturas. Porto Alegre: PUCRS, 2008, p. 35-58.

VEIGA-NETO, Alfredo. Currículo: um desvio à direita ou delírios avaliatórios. COLÓQUIO SOBRE QUESTÕES CURRICULARES, 10, 2012. Anais ... Belo Horizonte: UFMG, 2012.

VEIGA-NETO, Alfredo. Governamentalidades, neoliberalismo e educação. In: BRANCO, Guilherme; VEIGA-NETO, Alfredo (orgs.). Foucault, filosofia e política: Belo Horizonte: Autêntica, 2013, p. 35-50.

VEIGA-NETO, Alfredo. Currículo na Contemporaneidade: internacionalização e contextos locais. COLÓQUIO SOBRE QUESTÕES CURRICULARES, 11, 2012. Anais ... Braga: UMinho, 2014.

VEIGA-NETO, Alfredo; LOPES, Maura Corcini. Inclusão e governamentalidade. Educação \& Sociedade, Campinas, v. 28, n. 100, 2007, p. 947- 963.

VEIGA-NETO, Alfredo; LOPES, Maura Corcini. Inclusão, exclusão, in/exclusão. In: Verve, n. 20, 2011, p. 121-135.

Kamila Lockmann é professora no Programa de Pós-Graduação em Educação da Universidade Federal do Rio Grande.

Orcid: http://orcid.org/0000-0002-1993-8088.

Endereço: Rua Dr. Vaz Diaz Junior, 446/401 - 96050-500 - Rio Grande - RS - Brasil.

E-mail: Kamila.furg@gmail.com. 
Roseli Belmonte Machado é professora na Escola Superior de Educação Física, Fisioterapia e Dança da Universidade Federal do Rio Grande do Sul.

Orcid: http://orcid.org/0000-0001-5653-1175.

Endereço: Rua Cangussu, 236/404 - 90830-010 - Porto Alegre - RS - Brasil.

E-mail: robelmont@yahoo.com.br.

Recebido em 8 de novembro de 2019.

Aceito em 29 de dezembro de 2020.

(c) (i) 